\title{
A UTILIZAÇÃO DO SENSORIAMENTO REMOTO E GEOPROCESSAMENTO NA ANÁLISE DE SENSIBILIDADE AMBIENTAL AO ÓLEO EM AMBIENTES TERRESTRES: ESTUDO DE CASO DE TRECHO DA RODOVIA ANHANGUERA (SP-330)
}

\author{
Thamiris Cristina Costa Basilio ${ }^{(a)}$, Alexandre Magnum Leme ${ }^{(b)}$, Daniela Ferreira Ribeiro ${ }^{(c)}$, \\ Paulina Setti Riedel ${ }^{(d)}$
}

\footnotetext{
(a) Departamento de Geologia Aplicada - DGA / Universidade Estadual Paulista - UNESP/IGCE, Caixa Postal 178 13506-900 - Rio Claro - SP, Brasil, Email: thamiris.basilio@ gmail.com,

(b) Departamento de Geologia Aplicada - DGA / Universidade Estadual Paulista - UNESP/IGCE, Caixa Postal 178 - 13506-900 - Rio Claro - SP, Brasil, Email: alexandremagnumleme@ gmail.com

(c) Departamento de Geologia Aplicada - DGA / Universidade Estadual Paulista - UNESP/IGCE, Caixa Postal 178 13506-900 - Rio Claro - SP, Brasil, Email: danifebeiro@ gmail.com

(d) Departamento de Geologia Aplicada - DGA / Universidade Estadual Paulista - UNESP/IGCE, Caixa Postal 178 - 13506-900 - Rio Claro - SP, Brasil, Email: psriedel@ rc.unesp.br
}

\section{EIXO: GEOTECNOLOGIAS E MODELAGEM ESPACIAL EM GEOGRAFIA}

\begin{abstract}
Resumo
As rodovias se destacam como importantes áreas para os estudos de sensibilidade a derrames de óleo em ambientes terrestres uma vez que são um dos modais mais utilizados nas últimas décadas para o transporte de derivados de petróleo. As Cartas de Sensibilidade Ambiental ao Óleo (Cartas SAO) são um elemento essencial para o planejamento de ações mitigadoras de graves contaminações de solos e águas. Neste contexto, o estudo teve como objetivo demonstrar a eficiência das técnicas de geoprocessamento e sensoriamento remoto no desenvolvimento de Cartas SAO, em uma área-piloto localizada em um trecho da Rodovia Anhanguera. O resultado obtido foi uma carta de índices de sensibilidade ambiental ao óleo em ambiente terrestre com um Índice de Sensibilidade Terrestre (IST) médio-alto. Concluiu-se que a utilização do sensoriamento remoto e geoprocessamento foram eficientes para a análise da sensibilidade ambiental ao óleo em ambiente terrestre, especificamente, em rodovias.
\end{abstract}

Palavras chave: Cartas de Sensibiliade Ambiental ao Óleo (Cartas SAO), Derrames de óleo, Geoprocessamento, Rodovias.

\section{Introdução}

A indústria do petróleo teve início no século XIX e obteve seu desenvolvimento efetivo no século XX, tornando-se uma das atividades industriais mais importantes na atualidade, devido à sua grande importância como fonte de energia e matéria-prima de diversos bens de consumo. Entretanto, a ampla utilização dessa fonte de energia pode acarretar riscos ao meio ambiente e à saúde dos seres humanos devido à possibilidade de acidentes envolvendo vazamentos de óleo e também das características nocivas do mesmo, visto que o petróleo apresenta um alto nível de toxidade e é altamente inflamável. 


\section{OS DESAFIOS DA GEOGRAFIA FÍSICA NA FRONTEIRA DO CONHECIMENTO \\ Instituto de Geociências - Unicamp \\ Campinas - SP \\ 28 de Junho à 02 de Julho de 2017}

Os acidentes envolvendo derrames de óleo estão diretamente relacionados ao processo de transporte de hidrocarbonetos, sendo que os principais tipos de transporte se dividem em terrestres (ferroviário, rodoviário e dutoviário) e aquaviários. Os desastres ocorrem principalmente devido a colisões de navios, rompimento de dutos, explosões em plataformas e acidentes envolvendo veículos transportadores (ARAUJO et al., 2002).

Segundo a Companhia de Tecnologia de Saneamento Ambiental do Estado de São Paulo - CETESB, no Brasil o transporte de produtos petroquímicos é realizado principalmente pelo modal rodoviário, devido ao modelo de transporte adotado pelo país e ausência de malha dutoviária nacional adequada. Entretanto, segundo dados da Companhia Nacional de Transporte - CNT (2009), 69\% das rodovias brasileiras apresentam qualidade variando de ruim a péssima, possibilitando assim o aumento da probabilidade de ocorrência de acidentes.

Nesse contexto, são necessários estudos que subsidiem planos emergenciais, de forma a minimizar os danos causados por acidentes envolvendo derrames de óleo no ambiente. Por conseguinte, são utilizadas as Cartas de Sensibilidade Ambiental ao Óleo (Cartas SAO), que de acordo com Jensen et al. (1998), caracterizam-se como ferramentas que têm por objetivo reduzir as consequências ambientais dos vazamentos de óleo e tornar eficientes os esforços de contenção, limpeza e remoção. Essas cartas também são úteis no mapeamento e identificação de áreas sensíveis, antes que ocorram acidentes envolvendo derrames de petróleo e compondo ferramentas que auxiliem na identificação de áreas prioritárias de proteção, sendo possível delinear estratégias de proteção e limpeza antecipadamente (Ministério do Meio Ambiente - MMA, 2002).

\section{Objetivos}

O principal objetivo dessa pesquisa foi a aplicação da metodologia proposta por Martins (2012) para a geração de uma carta de índices de sensibilidade ambiental ao óleo, em um trecho da Rodovia Anhanguera (SP-330), demonstrando a eficiência da utilização de técnicas de sensoriamento remoto e geoprocessamento no desenvolvimento dessas cartas.

\section{3. Área de estudo}

A determinação da área de estudo se justifica devido às informações fornecidas pela Agência Nacional do Petróleo - ANP (2015), que mostram que a região Sudeste é uma das principais responsáveis pelo refino de petróleo no país. Além disso, de acordo com dados estatísticos fornecidos pela CETESB (2015), no ano de 2015 ocorreu um total de 221 acidentes envolvendo produtos perigosos em rodovias no estado de São 


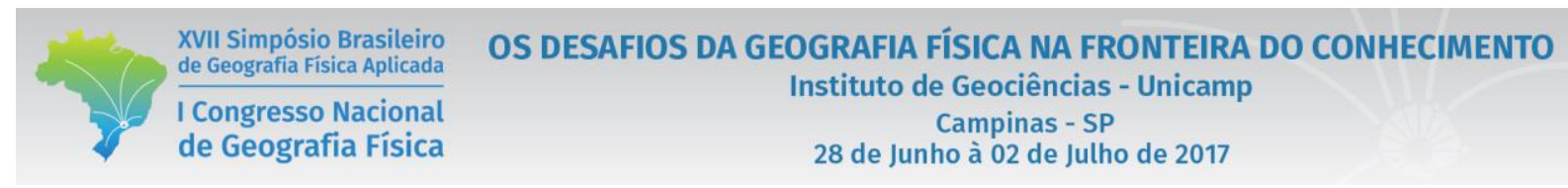

Paulo, sendo que a grande maioria dos acidentes envolveu derrames de gasolina, óleo diesel e álcool etílico. Ademais, no referido ano, a rodovia Anhanguera ocupou o terceiro lugar no ranking de quantidade de acidentes rodoviários envolvendo emergências químicas.

A Figura 1 apresenta a localização da área determinada para o referido estudo na região sudeste do município de Araras, SP.

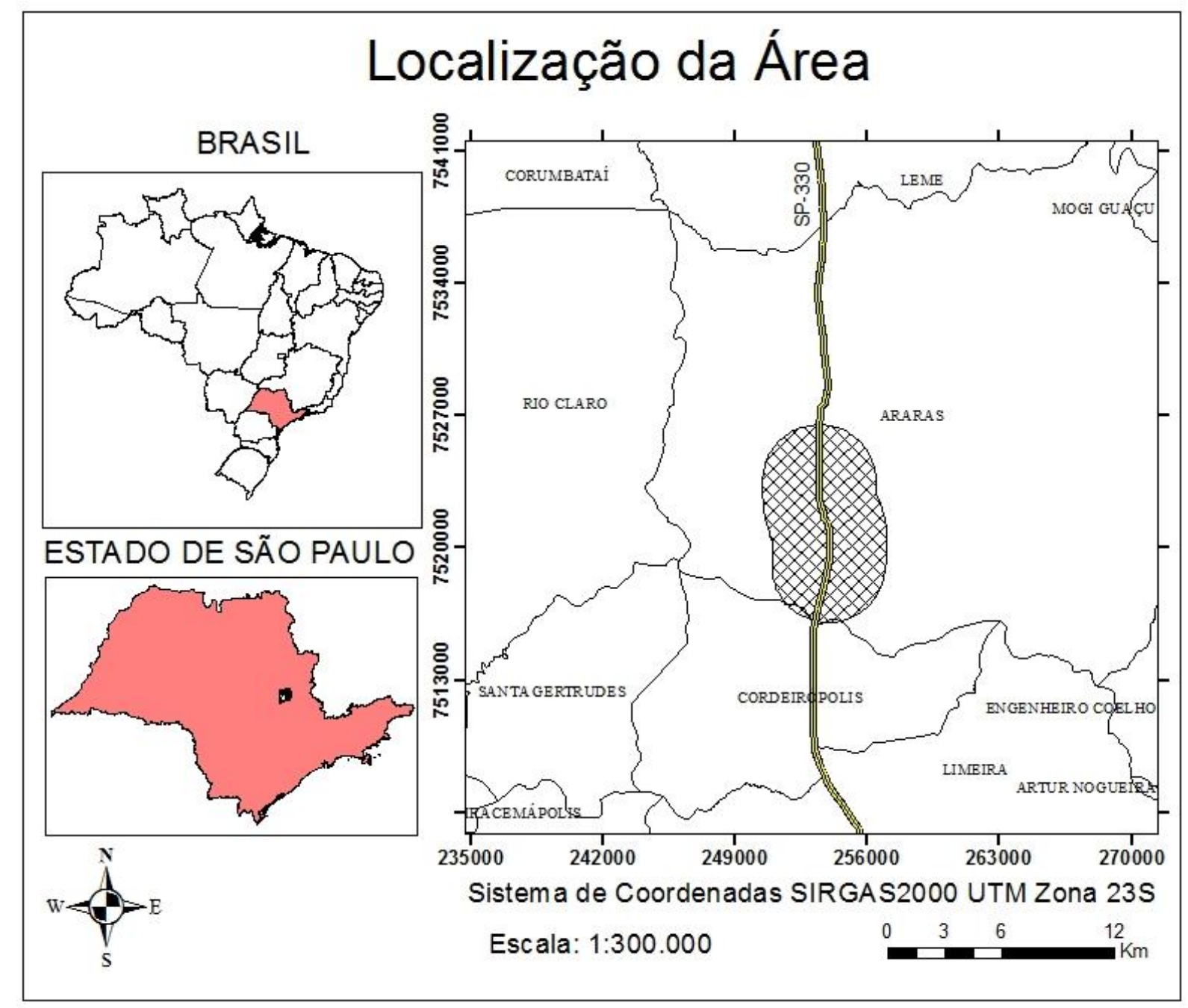

Figura 1- Localização da área de estudo.

\section{Materiais e Métodos}

A base cartográfica deste estudo foi gerada através da utilização dos recortes do mosaico de imagens ortorretificadas SPOT, através da fusão de bandas multiespectrais do satélite SPOT 5, com a banda pancromática, gerando um produto com 2,5m de resolução espacial, compatível com a escala 1:10.000. 
As imagens foram cedidas pela Coordenadoria de Planejamento Ambiental (CPLA) da Secretaria de Meio Ambiente do Estado de São Paulo, em formato GeoTiff, composição colorida RGB, datadas dentro do intervalo de anos de 2007 e 2010. O recorte segue a articulação 1:25:000 do IBGE (Instituto Brasileiro de Geografia e Estatística) com datum SIRGAS 2000 e Sistema de Projeção Universal Transversa de Mercator (UTM).

Além disso, foram utilizadas folhas topográficas na escala 1:10.000, obtidas através do Instituto Geológico do Sistema Ambiental Paulista de São Paulo (1979). Estas folhas foram georreferenciadas e vetorizadas no software ArcGIS (ESRI, 2015), onde também foi realizada a mudança de DATUM de Córrego Alegre para SIRGAS 2000. Efetuaram-se também levantamentos bibliográficos em acervos analógicos, como a biblioteca da Universidade Estadual Paulista Júlio de Mesquita Filho (UNESP), bem como em acervos digitais nacionais e internacionais. As informações coletadas foram armazenadas no software ArcGIS 10.2.2 (ESRI, 2015) e organizadas em um banco de dados utilizando um Sistema de Informação Geográfica (SIG).

Para a confecção do mapa de índices de sensibilidade ambiental ao óleo se utilizou a proposta de Martins (2012), que sugere a produção de um Índice de Sensibilidade Terrestre (IST) que apresenta como váriáveis os seguintes aspectos: a declividade do terreno, a textura e a profundidade do perfil de alteração, a profundidade do nível d'água e a permeabilidade relativa. Desta forma, os índices foram baseados nos processos físicos que controlam a deposição do óleo no ambiente.

Das técnicas de fotointerpretação e geoprocessamento utilizadas, destaca-se a compartimentação fisiográfica de trechos da região em estudo, a fim de determinar a persistência natural do óleo e sua facilidade de limpeza, por meio das características homogêneas da região, identificadas por esse método. Segundo Vedovello (1993), a compartimentação fisiográfica na imagem de sensoriamento remoto pode ser entendida como a identificação de divisões fisiográficas em diferentes níveis hierárquicos de classificação, relacionadas às condições morfoambientais e genéticas de uma dada região. $\mathrm{O}$ princípio utilizado na compartimentação é que os elementos fisiográficos são resultantes da interação de fatores litológicos, tectônicos, climáticos e mofogenéticos. Esta interação é apresentada sob formas particulares em cada região, determinando, desta forma, diferentes paisagens (VEDOVELLO; MATTOS, 1998).

A partir do exposto, no presente trabalho foi realizada a compartimentação física da área de estudo utilizando-se os critérios propostos por Zaine (2011). Os critérios escolhidos para a análise fisiográfica e as formas de análise dos parâmetros da área de estudo são apresentados na Figura 2.

A escolha dos critérios utilizados para a análise fisiográfica da área foi determinada de acordo com a sua relevância em relação à sensibilidade ambiental ao óleo. A partir da determinação dos critérios de análise, 


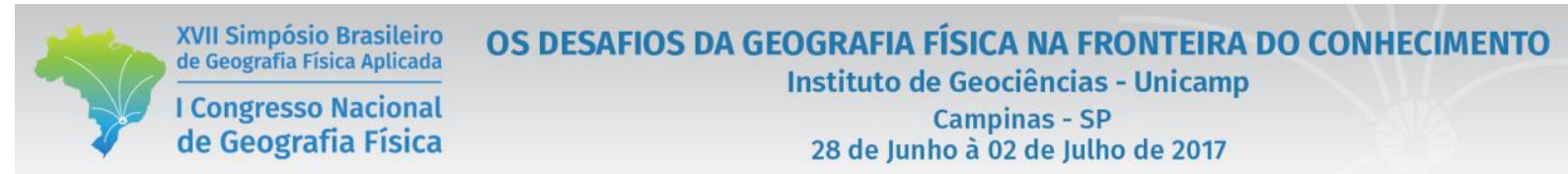

foi realizada a identificação das zonas homólogas da área de estudo, de forma manual, utilizando-se das imagens SPOT e modelo digital de elevação.

\begin{tabular}{|c|c|c|c|c|}
\hline \multicolumn{2}{|c|}{ 1. Análise da densidade textural } & \multicolumn{3}{|c|}{ CLASSES } \\
\hline $\begin{array}{l}\text { Elementos de } \\
\text { análise }\end{array}$ & \multicolumn{4}{|l|}{ Elementos de drenagem e relevo } \\
\hline $\begin{array}{l}\text { Critérios de } \\
\text { análise }\end{array}$ & $\begin{array}{l}\text { Densidade dos elementos de } \\
\text { drenagem }\end{array}$ & Baixa $\left(0\right.$ a $\left.5 / 10 \mathrm{~km}^{2}\right)$ & $\begin{array}{c}\text { Média }\left(5 \text { a } 30 / 10 \mathrm{~km}^{2}\right) \\
\cup \vee Y\end{array}$ & $\begin{array}{l}\text { Alta }\left(>30 / \mathrm{km}^{2}\right) \\
\end{array}$ \\
\hline $\begin{array}{l}\text { Propriedade a ser } \\
\text { interpretada }\end{array}$ & PERMEABILIDADE (intergranular) & $\begin{array}{c}\text { Alta } \\
\text { (Permeável) }\end{array}$ & Média & $\begin{array}{c}\text { Baixa } \\
\text { (Pouco permeángl a } \\
\text { impermeavel) }\end{array}$ \\
\hline \multirow{2}{*}{\begin{tabular}{|c|} 
APLICACOES \\
Informaḉes interpre- \\
tadas por esta anallise
\end{tabular}} & Relaçāo escoamento superficialinfiltraçāo & Baixa & Média & Alta \\
\hline & Espessura e caracteristicas do manto de alteraç̧o & $\begin{array}{c}\text { Grande } \\
\text { (Espesso; }>5 \mathrm{~m} \text { ) }\end{array}$ & Média & $\begin{array}{c}\text { Pequena } \\
\text { (Raso/rocha aflorante) }\end{array}$ \\
\hline
\end{tabular}

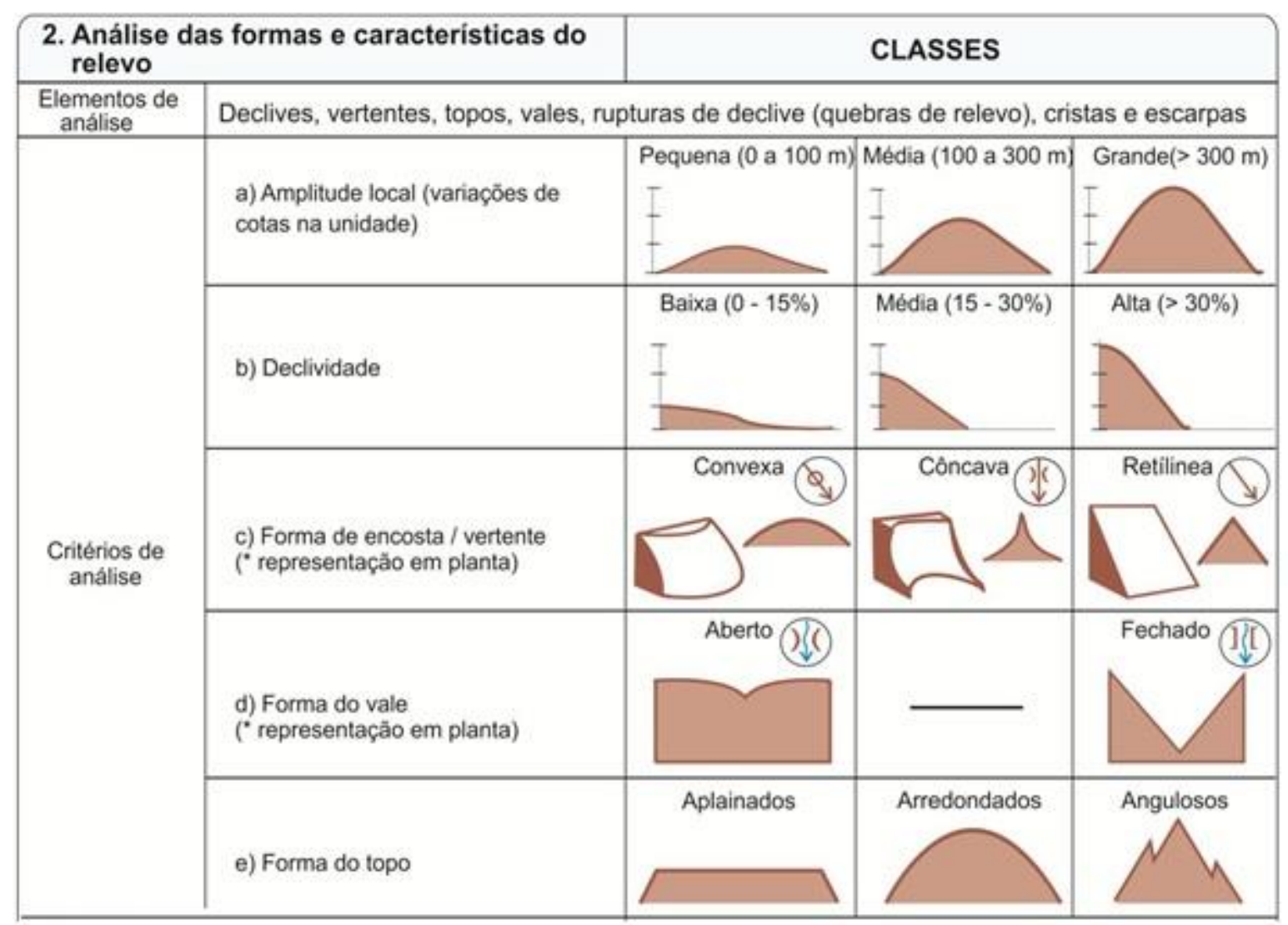

Figura 2- Síntese dos critérios adotados na compartimentação do relevo e propriedades analisadas.

Fonte: Zaine (2011). 


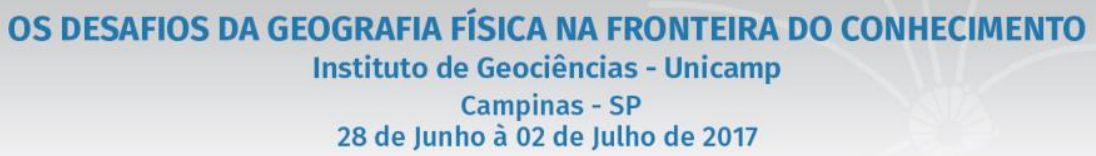

A compartimentação fisiográfica foi feita utilizando-se técnicas de fotointerpretação, segundo metodologia proposta por Zaine (2011), com o intuito de determinar os segmentos ambientais, com características homogêneas, para a realização da análise da sensibilidade ambiental ao óleo das feições. Nessa técnica o produto cartográfico gerado é único, porém seccionado em unidades do terreno que refletem as diferentes características referentes ao relevo, solo, geologia, dentre outros, cujas informações são sintetizadas e apresentadas como uma análise integrada (ZAINE, 2011).

A partir da geração do mapa de compartimentação fisiográfica, pôde-se iniciar a confecção do mapa de índices de sensibilidade ambiental ao óleo, visto que para isso foi necessário a compilação de diferentes características. As características "Declividade", "Densidade de Drenagem" e "Permeabilidade", analisadas nas unidades fisiográficas são relevantes em relação à sensibilidade ambiental ao óleo, podendo determinar a dinâmica do poluente no ambiente. Estes dados foram correlacionados com informações obtidas em outros mapas-base (mapa hipsométrico, mapa de profundidade do nível d'agua e mapa de densidade de fraturas) gerados para a determinação dos índices de sensibilidade ambiental.

Para a geração do mapa final com os valores de IST, foi necessária a utilização de uma ferramenta do software ArcGIS (ESRI, 2015), chamada weight sum (overlay), que trabalha com arquivos no formato raster, podendo assim, associar diferentes tipos de mapas (todos vetorizados e georreferenciados com as mesmas bases) e gerar uma superposição entre eles.

A weigth sum (overlay) permite ao usuário a escolha do peso de cada variável, representada na forma de um mapa parcial, para a geração de um mapa final com valores diferenciados, de acordo com seus objetivos.

\section{Resultados e Discussão}

A identificação das zonas homólogas a partir da compartimentação resultou em um banco de dados espacial, onde os polígonos correspondentes aos vários compartimentos receberam atributos referentes às diferentes variáveis-chave, consideradas relevantes com relação ao comportamento do óleo no meio terrestre, de forma a definir sua sensibilidade (MARTINS, 2008). Foram identificados oito compartimentos com características diferentes (Figura 3).

As variáveis-chave elencadas para a composição do IST são: (1) declividade (2) textura do material do perfil de alteração, (3) profundidade do perfil de alteração, (4) profundidade do nível d'água (lençol freático), e (5) densidade de drenagem.

Com o estabelecimento de classes para todas as variáveis do banco de dados, foi atribuída uma sensibilidade ambiental parcial (baixa, intermediária, alta) para cada uma delas, de acordo com a interação entre o óleo e as variáveis, conferindo uma cor característica a cada sensibilidade relativa e um valor para 


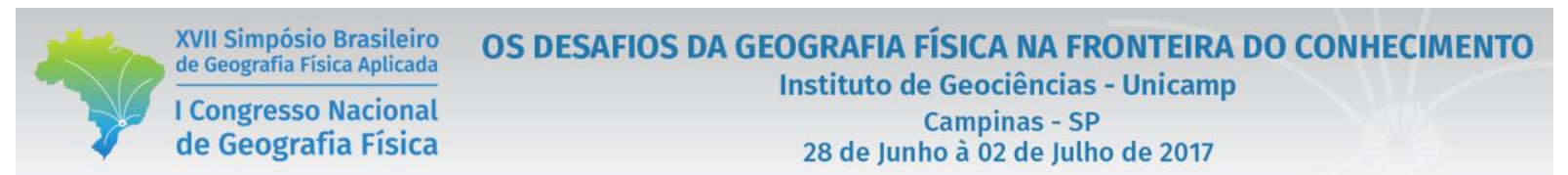

as mesmas. As cores e os valores utilizados foram os seguintes: vermelha para a classe com sensibilidade ambiental parcial alta e valor três; amarela para sensibilidade intermediária e um valor dois; e verde para a classe cuja sensibilidade fosse baixa, com um valor um.

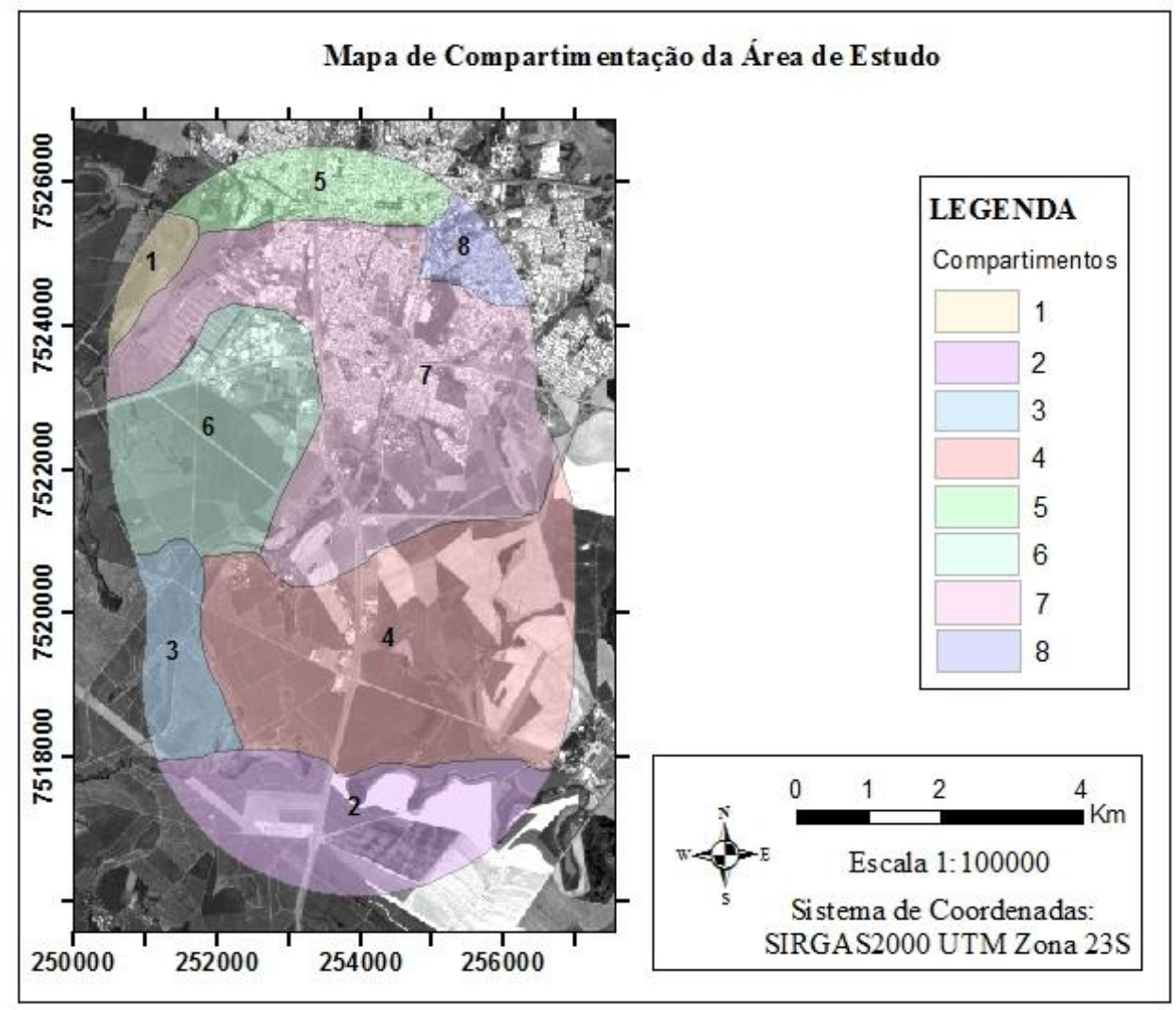

Figura 3. Mapa de Compartimentação da Área de Estudo.

Todas essas informações podem ser observadas detalhadamente na Tabela I.

Tabela I- Identificaçã das zonas homólogas e suas variáveis-chave.

\begin{tabular}{|c|c|c|c|c|c|c|c|c|}
\hline $\begin{array}{c}\text { Comparti- } \\
\text { mentos }\end{array}$ & $\mathbf{1}$ & $\mathbf{2}$ & $\mathbf{3}$ & $\mathbf{4}$ & $\mathbf{5}$ & $\mathbf{6}$ & $\mathbf{7}$ & $\mathbf{8}$ \\
\hline Unidades & $\begin{array}{c}\text { Formação } \\
\text { Corumba- } \\
\text { taí }\end{array}$ & $\begin{array}{c}\text { Forma- } \\
\text { ção } \\
\text { Tatuí }\end{array}$ & $\begin{array}{c}\text { Formação } \\
\text { Corumba- } \\
\text { taí }\end{array}$ & $\begin{array}{c}\text { Formação } \\
\text { Serra } \\
\text { Geral }\end{array}$ & $\begin{array}{c}\text { Formação } \\
\text { Serra } \\
\text { Geral }\end{array}$ & $\begin{array}{c}\text { Forma- } \\
\text { ção } \\
\text { Tatuí }\end{array}$ & $\begin{array}{c}\text { Formação } \\
\text { Tatuí }\end{array}$ & $\begin{array}{c}\text { Grupo } \\
\text { Itararé }\end{array}$ \\
\hline $\begin{array}{c}\text { Peso da } \\
\text { Classificação }\end{array}$ & $\mathrm{P} 1$ & $\mathrm{P} 1$ & $\mathrm{P} 1$ & $\mathrm{P} 1$ & $\mathrm{P} 1$ & $\mathrm{P} 1$ & $\mathrm{P} 1$ & $\mathrm{P} 1$ \\
\hline $\begin{array}{c}\text { Densidade de } \\
\text { Drenagem }\end{array}$ & $\begin{array}{c}\text { Muito } \\
\text { baixa }\end{array}$ & Baixa & Baixa & Baixa & Baixa & $\begin{array}{c}\text { Muito } \\
\text { Baixa }\end{array}$ & Média & $\begin{array}{c}\text { Muito } \\
\text { Baixa }\end{array}$ \\
\hline $\begin{array}{c}\text { Ponderação da } \\
\text { Densidade de }\end{array}$ & 3 & 3 & 3 & 1 & 1 & 3 & 2 & 3 \\
\hline
\end{tabular}


XVII Simpósio Brasileiro de Geografia Física Aplicada

I Congresso Nacional de Geografia Física
OS DESAFIOS DA GEOGRAFIA FÍSICA NA FRONTEIRA DO CONHECIMENTO

Instituto de Geociências - Unicamp

Campinas - SP

28 de Junho à 02 de Julho de 2017

\begin{tabular}{|c|c|c|c|c|c|c|c|c|}
\hline Drenagem & & & & & & & \\
\hline Declividade & Baixa & Baixa & Baixa & Baixa & Baixa & Baixa & Média & Baixa \\
\hline $\begin{array}{c}\text { Ponderação da } \\
\text { Declividade }\end{array}$ & 3 & 3 & 3 & 3 & 3 & 3 & 2 & 3 \\
\hline Textura & Argila & Areia & Areia & Areia & Argila & Areia & Areia/Argila & Argila \\
\hline $\begin{array}{c}\text { Ponderação da } \\
\text { Textura }\end{array}$ & 1 & 3 & 3 & 3 & 1 & 3 & 2 & 1 \\
\hline Espessura & Média & Alta & Alta & Alta & Média & Alta & Média & Média \\
\hline $\begin{array}{c}\text { Ponderação da } \\
\text { Espessura }\end{array}$ & 2 & 1 & 1 & 1 & 2 & 1 & 2 & 2 \\
\hline Prof. do NA & Médio & $\begin{array}{c}\text { Profun- } \\
\text { do }\end{array}$ & Raso & Raso & Médio & Raso & Raso & Médio \\
\hline $\begin{array}{c}\text { Ponderação da } \\
\text { Profundidade } \\
\text { do NA }\end{array}$ & 2 & 1 & 3 & 3 & 2 & 3 & 3 & 2 \\
\hline IST Parcial & 11 & 11 & 13 & 11 & 09 & 13 & 11 & 11 \\
\hline
\end{tabular}

Após essa análise e a geração de um IST parcial, foi necessária a reclassificação desse valor (0-13) em um índice de 0 a 10, para que assim fosse possível a integração entre esses valores do terrestre com o índice feito pelo Ministério do Meio Ambiente (2002), baseado no manual norte-americano elaborado pela National Oceanic and Atmospheric Administration (NOAA), para as áreas costeiras. Essa integração entre o ambiente costeiro e o terrestre é necessária, pois nenhum ambiente é independente do outro.

A partir das adaptações feitas no IST para a execução do Mapa Índice de Sensibilidade Ambiental ao óleo, em trecho da Rodovia Anhanguera, pôde-se confeccionar cinco mapas preliminares de sensibilidade, cada um com valores de 1-3, referentes às variáveis-chave, isoladamente (Figura 4).

Após a análise isolada de cada variável-chave pôde-se confeccionar o mapa de índices de sensibilidade ambiental ao óleo de um trecho da Rodovia Anhanguera, o qual mostrou a área como altamente sensível, visto que dos oito compartimentos, nenhum deles apresentou um IST menor do que 6 e que apenas um deles apresenta o IST 6, que já é considerado um IST médio - alto; cinco compartimentos apresentaram um IST 8 e dois compartimentos apresentaram um IST 9, sendo que o nível máximo desses índices chegaria a 10, como pode ser observado na Figura 5, que mostra o mapa de índices de sensibilidade ambiental ao óleo já com a reclassificação final baseada nas normas do MMA (2002). 


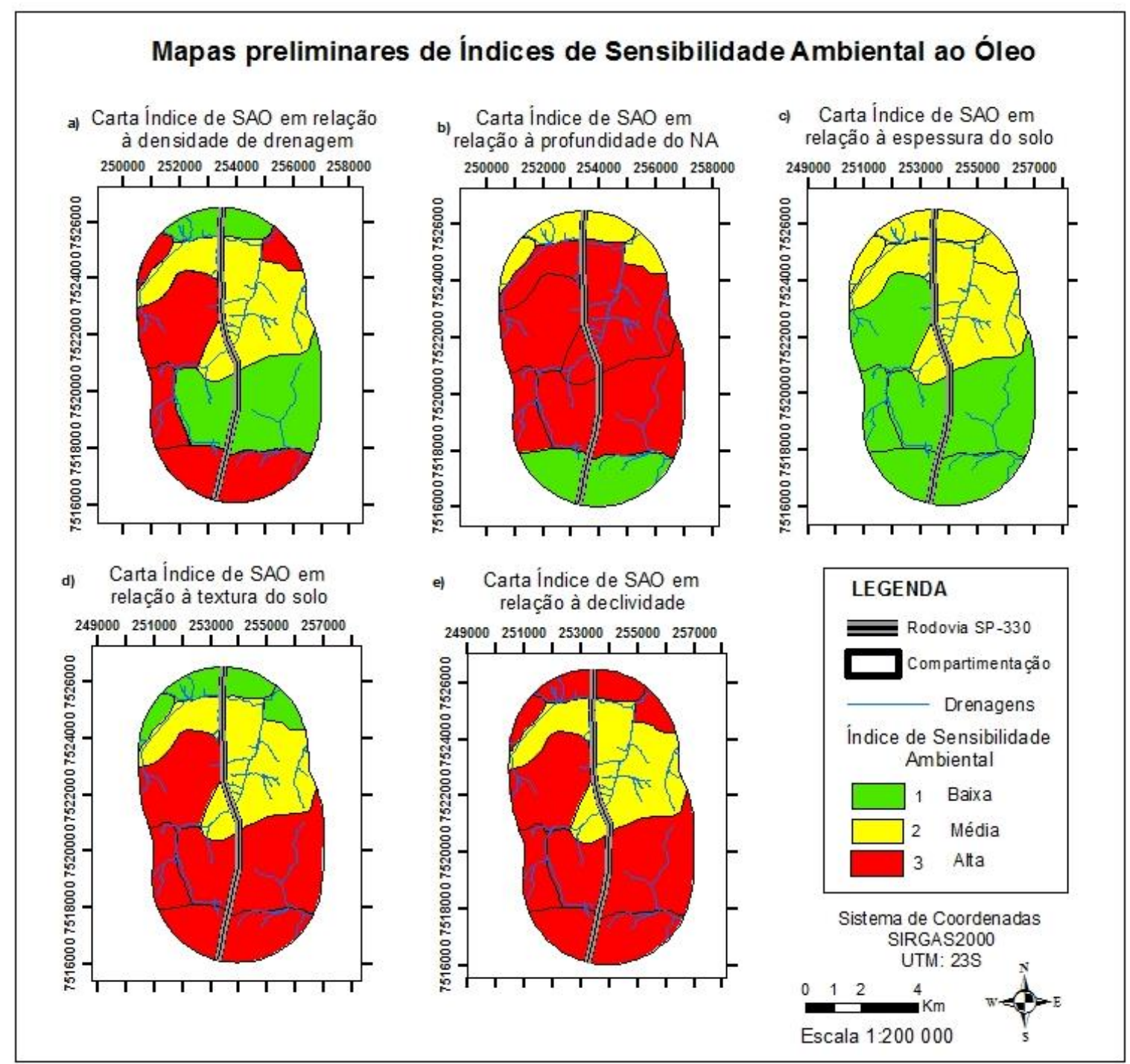

Figura 4- Mapas preliminares de Índices de Sensibilidade Ambiental ao Óleo em ambiente terrestre. 

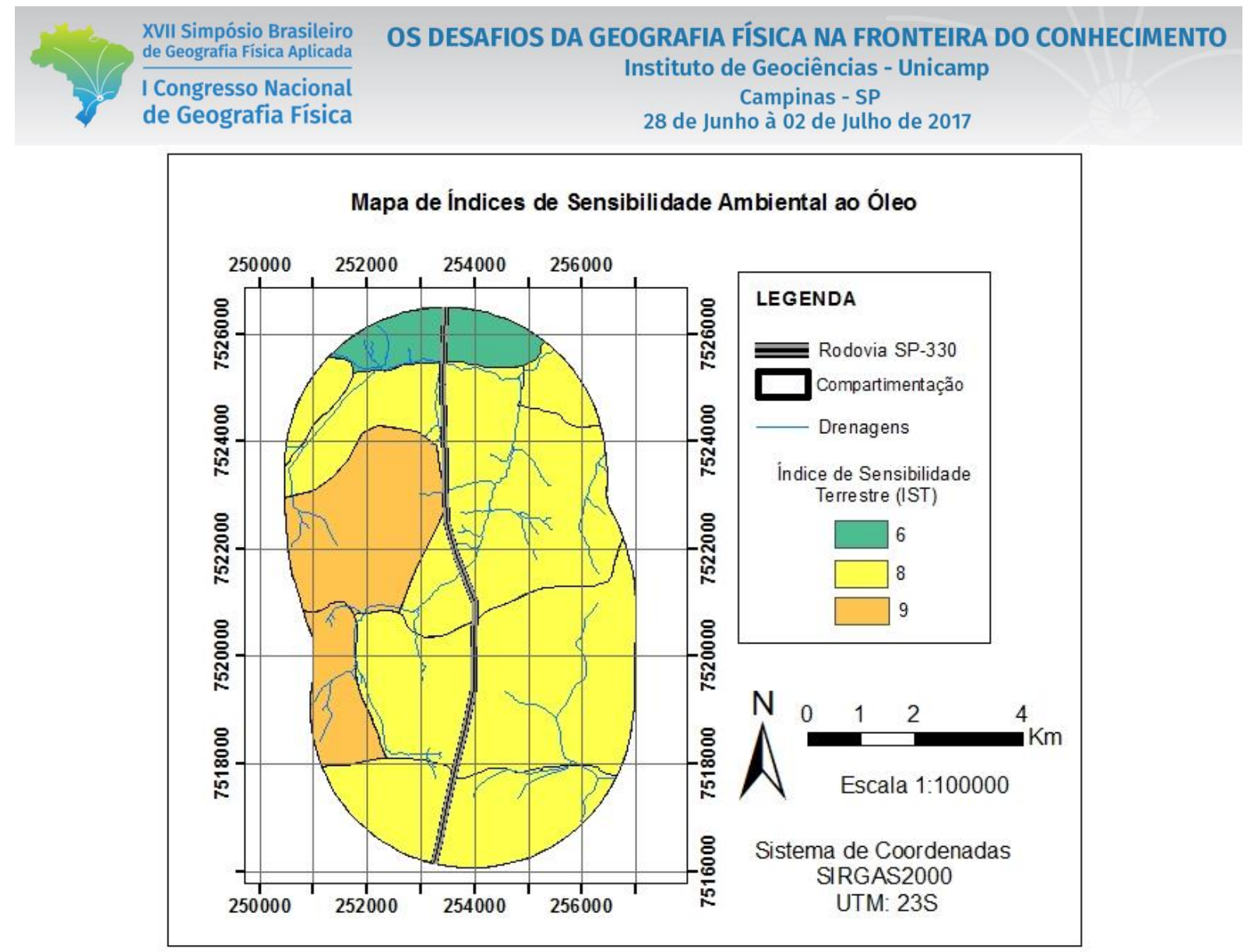

Figura 5- Mapa de Índices de Sensibilidade Ambiental no ambiente terrestre.

\section{Considerações Finais}

O mapeamento dos índices de sensibilidade ambiental ao óleo de um trecho da Rodovia Anhanguera indica a variedade de ambientes que podem ser contemplados com a elaboração dessas Cartas SAO e que os de alta sensibilidade (IST 8 e 9 sendo 10 o máximo) abrangem praticamente toda a área de estudo, exceto ao norte onde ocorre o IST 6, que já é considerado médio a alto. Portanto, toda área requer alerta constante.

As técnicas de sensoriamento remoto e o geoprocessamento foram ferramentas úteis e eficientes para a realização do estudo proposto, visto que possibilitaram uma compreensão global da área, além de colaborar com a interpretação das características físicas da região de interesse à sensibilidade ambiental ao óleo em ambientes terrestres, neste caso específico, do entorno de rodovias.

\section{Referências}

ANP, Agência Nacional de Petróleo. Anuário Estatístico Brasileiro de Petróleo, Gás e Biocombustíveis 2015. ANP, Rio de Janeiro, 2015

ARAUJO, S. I; SILVA, G. H.; MUEHE, D. C. E. H. Manual básico para elaboração de mapas de sensibilidade ambiental a derrames de óleo no sistema Petrobras: ambientes costeiros e estuarinos. Rio de Janeiro: 2002. 134p. 
Companhia Ambiental do Estado de São Paulo - CETESB. Cadastro de Emergências Químicas - Quadro de estatísticas 2015. Disponível em: 〈http://www.cetesb.sp.gov.br/emergencia/estatisticas/estatisticas.asp>. Acesso em 03 abril. 2015.

Companhia Ambiental do Estado de São Paulo - CETESB. Gerenciamento de riscos. Disponível em: <http://www.cetesb.sp.gov.br>

Confederação Nacional do Transporte - CNT. Pesquisa CNT de rodovias 2009: relatório gerencial. Brasília: CNT: SEST: SENAT, 2009. 152p.

ESRI. ArcGIS Desktop: Release 10. Redlands, CA: Environmental Systems Research Institute. 2015

JENSEN, J. R.; HALLS, N. J.; MICHEL, J. A system approach to environmental sensitivity index (ESI) mapping for oil spill contingency planning and response. Photogrammetric Enginnering \& Remote Sensing. v. 64, n.10, p. 1003-1014, 1998.

MARTINS, P. T. A. Carta de sensibilidade ambiental para derramamentos de óleo em rodovias: proposta aplicada a Estrada dos Tamoios (SP - 099). Tese (Doutorado em Geociências). Instituto de Geociências e Ciências Exatas, Universidade Estadual Paulista. Rio Claro. 2012. 172 f

Ministério do Meio Ambiente - MMA. Especificações e normas técnicas para a elaboração de cartas de sensibilidade ambiental para derramamentos de óleo. Rio de Janeiro: MMA, 2002, 22p.

VEDOVELLO, R. Zoneamento Geotécnico com base em Sensoriamento Remoto para fins de Planejamento Regional e Urbano [Geotechnical Zoning based on Remote Sensing Techniques for Urban and Regional Planning]. M. Sc, INPE_-National Institute for Space Research (in Portuguese), 1993.

VEDOVELLO, R.; MATTOS, JT de. A utilização de unidades básicas de compartimentação (UBCs) como base para a definição de unidades geotécnicas: uma abordagem a partir de sensoriamento remoto. Simpósio Brasileiro de Cartografia Geotécnica, v. 3, 1998.

ZAINE J. E. 2011. Método de fotogeologia aplicado a estudos geológico-geotécnicos: ensaio em Poços de Caldas, MG. Tese de Livre docência - Instituto de Geociências e Ciências Exatas, Universidade Estadual Paulista, Rio Claro. 